\title{
Group norms, physical distance, and ecological efficiency in common pool resource management
}

\author{
Wernher M. Brucks, Ulf-Dietrich Reips, and Bettina Ryf \\ University of Zurich, Switzerland
}

\begin{abstract}
Earlier research has repeatedly shown that people tend to follow group norms when using common pool resources. The present commons dilemma study seeks to extend these findings with two inherently relevant concepts: First, the ecological efficiency of the group norm, and second, the physical distance between the actors involved. Physical distance was manipulated by administering a web-based commons dilemma task to participants in the laboratory versus participants in the Internet. Ecological efficiency was manipulated by giving participants feedback about an overusing or a conserving group norm while the pool was either big or small. Conformity effects were strongest when the perceived group norm was ecologically efficient and participants were physically closer. Moreover, the effect of physical distance was mediated by the importance a person attached to the group's behavior. When physically farther apart, individuals attached less importance to the group's behavior and, as a consequence, showed less conformity. The results are discussed in the light of previous commons dilemma research and social psychological theories, and consequences for natural resource management are reflected.
\end{abstract}

Some common pool resources and the environmental problems associated with them are rooted on a local level (e.g., residential waste disposal or fresh water use), but others have a rather global dimension (e.g., air pollution or the greenhouse effect). Although local problems may often affect us more than global ones, both types of environmental problems are an integral part of our everyday life and local action is often relevant for global resources as

\footnotetext{
Address correspondence to: Wernher M. Brucks, University of Zurich, Department of Social Psychology, Binzmühlestrasse 14 / Box 15, CH - 8052 Zürich, Switzerland. E-mail: brucks@sozpsy.unizh.ch

This paper is partly based on the first author's doctoral dissertation and partly on the third author's diploma thesis. It was presented at the 14th General Meeting of the European Association for Experimental Social Psychology, in Würzburg, Germany, July 2005. We thank Anna Clark, the editor, and two anonymous reviewers for substantial advice on an earlier version.
} 
well. In the present contribution, we argue that these two forms of environmental problems (global vs local) may be connected with several social psychological processes related to people's adherence to group norms (e.g., Kallgren, Reno, \& Cialdini, 2000).

The idea that a person's tendency to conform to a group norm of consumption behavior may vary as a function of the physical distance between the actors involved is well captured in Latanés Theory of Social Impact (e.g., Latané, 1981), recently also known as Theory of Dynamic Social Impact (e.g., Latané, 1996). The closer people are to each other when managing a common pool, the more they may be willing to adhere to a given group norm. In most cases one can think of, individuals sharing a local resource (e.g., fresh water) are physically closer to each other than individuals sharing a global resource (e.g., a clean atmosphere). Thus, the Theory of Social Impact suggests that the sharing of local resources should depend more on perceived group norms than the sharing of local resources.

At the same time, other motives than conformity may also play a role for an individual's consumption behavior. People may only be willing to gravitate towards the consumption pattern of their close neighbors when it is ecologically efficient because they have a strong motive to preserve the common pool resource from being depleted (see Wilke, 1991). If others' consumption is relatively high but resources are scarce, people may be less inclined to conform than in a situation where resources are abundant and over-consumption would be less harmful.

Thus, with the present research we propose novel boundary conditions to the well-established finding that people generally tend to follow others' consumption behavior in situations of common pool resource management (e.g., Schroeder, Jensen, Reed, Sullivan \& Schwab, 1983). The knowledge of these boundary conditions may be relevant for at least two reasons. First, progress in the social sciences is made not only by finding main effects of certain factors but also by exploring their scope of validity. In the case of group norms in common pool resource management, this has not been done in the past. Second, the knowledge of boundary conditions for the effectiveness of group norms may lead to new and better approaches in directing people's behavior towards the sustainable use of common pool resources.

Our hypotheses are based on Latané's Theory of Social Impact (1981) and on Wilke's GEF Hypothesis (1991). To test them, we employed a commons dilemma experiment (see Kopelman, Weber, \& Messick, 2002) with preprogrammed feedback about an efficient vs inefficient group norm. We conducted the experiment in the laboratory (i.e., small physical distance between actors) and in the Internet (i.e., big physical distance between actors), and measured the amount of resources (i.e., points) the participants took out of a virtual common pool. 


\section{GROUP NORMS IN COMMON POOL RESOURCE MANAGEMENT}

In the present context, group norms are defined as "what most people do" in a given situation. This kind of group norm has been called descriptive norm (see Cialdini, Kallgren, \& Reno, 1991; Kallgren et al., 2000), in contrast to prescriptive group norms. Descriptive group norms are known to influence individual behavior in many situations of mutual interdependence, besides other general interaction norms such as the norm of reciprocity, for example (see Kerr, 1995, for an overview). As one instance for a situation of mutual interdependence, a group of people may be sharing a common pool of energy. For example, a settlement may be connected to an embankment dam or a solar power system that delivers a limited amount of energy, which represents the common pool. Previous research has repeatedly shown that people are generally inclined to conform to descriptive norms under such circumstances (e.g., Schroeder et al., 1983).

Schroeder et al. (1983), for example, found that the actions of others had a major influence on the behavior of individuals in a commons dilemma where participants share a common pool of points. Their participants immediately conformed to the feedback they received about others' consumption behavior. As an explanation, Schroeder et al. argued that others' consumption behavior helps define the situation. It reduces the uncertainty of how to act in the ambivalent situation of a commons dilemma where immediate individual welfare (i.e., using the common pool) and long-term collective welfare (i.e., preserving the common pool) are at odds.

Other laboratory studies have already analyzed boundary conditions for conformity in common pool resource management. For example, people showed a stronger tendency to follow the behavior of the group when they believed the group to be the main cause for the actual size of the common pool resource (e.g., Messick, 1986; Rutte, Wilke, \& Messick, 1987; Samuelson, Messick, Wilke, \& Rutte, 1986). When the size of the common pool resource (i.e., the points left in the common pool) seemed to have natural causes such as a diminished regeneration rate, people showed less conformity and acted ecologically more efficiently. This phenomenon has also been reported in a field study of water conservation in California (Talarowski, 1982). People who used more water than they were allocated tended to believe that the shortage was caused by others who were also overusing, whereas people who stayed within their allocation felt that the shortage was truly natural.

Conformity effects in common pool resource management also depend on individual characteristics such as trust (e.g., Messick et al., 1983) or a person's social values (e.g., Kramer, McClintock, \& Messick, 1986). When 
the common pool resource is overused by the group, people who have high trust in others and people with prosocial motivations do not follow the collective overuse but rather adapt their behavior in response to the declining pool by reducing their consumption. Low-trusters and selfish people, on the other hand, are more inclined to follow others' overuse and reduce their consumption in a resource shortage to a much lesser extent than prosocials or high-trusters.

In sum, there is a reasonable amount of evidence that group norms are an important guideline for individual consumption behavior in common pool resource management, and some boundary conditions for these conformity effects have been identified so far. Considering the distinction between local and global common pool resources points to another relevant boundary condition for conformity effects, the physical distance between the actors involved.

\section{PHYSICAL DISTANCE AND CONFORMITY TO GROUP NORMS}

In common pool resource management, the physical distance between the actors involved may vary to a large degree. In a group sharing a global common pool such as the earth's atmosphere, the physical distances between the actors are usually rather large. On the other hand, in a situation such as glass recycling or fresh water use in a local neighborhood, the physical distances between the actors are shorter and others' presence is much more immediate. Importantly, the physical distance between the actors may moderate the effects of group norms according to Latanés Theory of Social Impact (1981), recently also known as Theory of Dynamic Social Impact (Latané, 1996).

Social Impact Theory (SIT) states that immediacy (I), as well as the strength (S) and number $(\mathrm{N})$ of other people, make up social influence (i) in a multiplicative manner $(\mathrm{i}=\mathrm{SIN})$. Most important for the present purpose, the more immediate others are (i.e., closeness in space or time, visual as well as vocal contact, etc.) the stronger the social impact they have on an individual. Therefore, one may suspect that individuals using a local common pool are more inclined to conform with others' consumption patterns than individuals involved in the management of a global common pool. For example, it may make a difference if a rather compact settlement with well-defined boundaries is connected to a solar power system or if several houses that are scattered over a wider area are connected to it. In the former case the individuals are physically closer to each other than in the latter case, and therefore people may be more inclined to follow the consumption patterns of most others. This example also shows that physical distance and the "globality" of resources are theoretically separate 
constructs although they often co-vary. A local resource can sometimes be managed by a small group of well-defined others, located at a distance. Compared to the amount of supporting research about the effects of number of sources or targets (e.g., Jackson \& Latané, 1981; Latané \& Harkins, 1976), the immediacy concept has received only limited attention so far. To our knowledge, immediacy in the context of cooperation in groups or the management of common pool resources has not been studied at all. Moreover, most studies on physical distance yielded mixed results and only partial support for Social Impact Theory.

In his meta-analysis, Mullen $(1985,1986)$ found that immediacy tended to exert an influence on self-report measurements of subjective anticipated tension, but not so much on other measurements that are closer to overt behavior. Although Jackson (1986) criticized Mullen's methodological approach and defended the existence of immediacy effects on overt behavior, not much support for Jackson's claims can be found in the literature until today. Early studies found only small effects on donations (Jackson \& Latané, 1981) or maze learning (Knowles, 1983, study 3), and a recent study on minority influence found no main effect of immediacy at all (Hart, Stasson, \& Karau, 1999). The closest approach to overt behavior was taken by studies in naturalistic settings like a zoo (Sedikides \& Jackson, 1990) or a retail store (Argo, Dahl, \& Manchanda, 2005). Whereas it was found that zoo visitors tended to follow the experimenter's instructions not to lean on the rails in front of a birds' cage the more immediate that person was, no main effect of immediacy was found on customers' selection of a battery brand in a retail store.

One reason for these weak and inconsistent effects may be found in the way that immediacy has been operationalized in the past. In many instances, it involved some indication of interpersonal distance, measured in physical units such as feet or meters. For example, operationalizations included the distance door-to-door solicitors stood from the door (Jackson \& Latané, 1981), the distance with which a camera shot was taken of a source of social influence (Wolf \& Latané, 1981), or the distance a confederate was situated from the target of social influence in a retail store setting (Argo et al., 2005). First of all, we suspect that most of these manipulations were not strong enough to warrant the desired perceptions of physical distance in the targets of influence. Distance differences of a few feet-or meters - may not be relevant enough to elicit effects on conformity. What is considered a relevant distance likely depends on the context: In an office or in a retail store, a small difference between distances of a few feet may already matter. Nevertheless, one may speculate that bigger differences in distance will result in stronger differences between effects of social influence. For example, in a series of surveys, Latané, Liu, Nowak, and Bonevento (1995) found that the 
number of memorable interactions decreased as a function of geographical distance-ranging from 0.001 to 10,000 kilometers - raised to the first power (see also Knowles, 1999, for an interpretation of these results). However, a sufficiently strong manipulation of immediacy, including distance differences of thousands of miles, is missing in research using a controlled laboratory setting.

Many researchers - including Latané himself (1981) — have also argued that immediacy is a multidimensional construct consisting of physical and psychological components (e.g., Monge, Rothman, Eisenberg, Miller, \& Kirste, 1985; Valacich, George, Nunamaker, \& Vogel, 1994). And indeed, many operationalizations of immediacy incorporate a psychological dimension, in that the targets of social influence not only perceive the physical distance as such but also an additional psychological distance between the source of influence and themselves. For example, a closer physical distance may also elicit stronger feelings of entitativity or group identity because in most cases, small physical distances are also associated with smaller groups and greater intimacy. Importantly, a strong group identity may lead to more conformity within the group, and therefore it may confound the effects of physical distance. Interestingly, the confounding effect can also work the other way around. For example, physical closeness may also even out prior differences in status because people high in status tend to keep a certain distance from people of lower status. This can lead to a situation where conformity is higher when the source of influence is distant because a higher status is ascribed to that person (e.g., Hart et al., 1999; Lott \& Sommer, 1967).

The problem of confounding variables is particularly present in field studies on immediacy, but also laboratory research has not completely succeeded in isolating the effects of physical distance. In sum, past efforts to manipulate immediacy were probably not effective enough to show the effects that physical distance can have on conformity. The rather novel possibility of using the Internet as a tool for conducting experiments is opening new perspectives, because it is common knowledge that the distance between Internet users can naturally vary between a few meters in an office building and thousands of kilometers on different continents. When we are interacting with others via the Internet we are mostly ignorant of the distances between us and others, unless we receive specific information about it. At the same time, the computer-mediated way of interacting via the Internet makes it possible to hold constant most other variables, such as a person's appearance or voice, and other distractions that naturally occur in group studies. Therefore, Internet-based group research offers a good opportunity to control variables that are otherwise confounding the effects of pure physical distance on conformity. 


\section{ECOLOGICAL EFFICIENCY OF GROUP NORMS AND CONFORMITY}

Let us assume that group norms are effective because the actors involved are physically close to each other. In this case, we would propose that it may still happen that people are not conforming because the perceived group norm is ecologically inefficient. The efficiency of a group norm is defined as the proportionality of the group norm with regard to the actual size of the common pool resource. This definition is best understood by means of an example. If residents of a small settlement get the impression that most others are using too much energy from the common solar power plant, they may be inclined to follow that overuse. If, at the same time, they get the impression that the energy supply is very low, which does not allow a more intensive consumption, they are in a conflict between saving and using energy. This may weaken their original motive to conform because wasting energy in that situation would not be efficient. With the GEF hypothesis, Wilke (1991) described this conflict of motives in common pool resource management.

The GEF hypothesis postulates three motives that guide human behavior in situations of common pool resource management: Greed, Efficiency, and Fairness. The greed motive describes an individual's tendency to make as much profit from the management of a common pool as possible. The efficiency motive represents an individual's desire to manage the pool in a sustainable way in order to keep it going as long as possible. The fairness motive defines an individual's striving for fairness with regard to the allocations that are made by the members of a group. Striving for fairness can imply conformity, because it may lead an individual to adjust his or her own consumption to the others' consumption.

People may tend to follow others' high use when resources are abundant and others' low use when resources are scarce in order to maintain fairness, because both of these outcomes also agree with the individual's motive to use the pool efficiently. By overusing an abundant resource no harm is done, and by conserving a scarce resource possible damage is prevented. In contrast, an ecologically inefficient group norm may be less followed because the efficiency motive comes into play and conflicts with the fairness motive. Following others' low use in times of abundance may be constrained by the efficiency consideration that enough resources are available. In the same way, following others' high use in times of scarcity may be constrained by the efficiency consideration that the pool has to be preserved. To sum up our reasoning, the effects of distance on conformity may be moderated by considerations of ecological efficiency in that distance only matters when the consumption behavior of others accords with the availability of resources. 


\section{THE PRESENT RESEARCH}

To put our assumptions to the test we used the experimental paradigm of the "Solar Energy Group Game" (SEGG; see Brucks, 2004). The SEGG is a repeated commons dilemma task with completely pre-programmed feedback about the pool and about others' behavior. A group of six persons is supposed to share the energy of a solar power supply. The SEGG can be accessed via the Internet, ${ }^{1}$ which made it easy to manipulate the physical distance between the participants. Individuals either participated via the Internet where their physical distance is naturally bigger, or they came to the laboratory where they were supposedly sitting close to each other but in separate rooms. In both cases, a computer wrote participants' decisions to a $\log$ file that was later processed with the Scientific Log Analyzer (Reips \& Stieger, 2004). ${ }^{2}$

The group norm is manipulated in the SEGG by providing participants with false feedback about the consumption behavior of the whole group of six persons (see Crutchfield, 1955), and no feedback about individual behavior is given. Over the course of the task the common pool is preprogrammed to decrease for all participants, while the simulated group norm is changing from high consumption to low consumption for one half of the participants (i.e., ecologically efficient condition) and from low to high consumption for the other half of the participants (i.e., ecologically inefficient condition). When the pool is decreasing it would be an efficient behavior to consume a lot in the beginning and conserve at the end of the task, but it would be inefficient to begin the task with conserving and then consume a lot at the end. The present manipulation of group norms provides us with the opportunity to observe compliance to efficient group norms (i.e., overusing an abundant pool but conserving a scarce pool) as well as compliance to inefficient group norms (i.e., overusing a scarce pool or conserving an abundant pool).

With the present study, we expect to replicate the general finding that participants follow the feedback about the group's consumption behavior. Specifically, we expect a within-subject interaction effect between the pool

\footnotetext{
${ }^{1}$ The Solar Energy Group Game (SEGG) and the Web Experimental Psychology Lab are accessible at: http://tinyurl.com/dwcpx)

${ }^{2}$ To date, the Internet is an established medium for data collection in the social sciences. Research has demonstrated that, in general, data collected through the Internet are of at least equal quality to laboratory data, if the proper instruments for this type of data collection are used (Reips, 2002a) and established standards are adhered to (Reips, 2002b). The SEGG was designed with all known and possible preconditions to ensure the quality of the data collected via the Internet. For example, by checking the Internet Protocol (IP) addresses, operating system, and web browser of the computers that participants used, it was possible to identify potential multiple submissions.
} 
size and the feedback people receive about the group norm. Receiving feedback about an efficient group norm should result in more consumption than receiving feedback about an inefficient group norm when the pool is big, but in less consumption when it is small. More important, we seek to extend this replication by hypothesizing that physical distance further qualifies the effects of conformity in the sense of a three-way interaction. In particular, individuals in the laboratory should conform more to the group norm than individuals participating via the Internet. Finally, the moderating effects of physical distance are expected to be stronger when the group norm is ecologically efficient, which is the case for a norm of over-consumption at the beginning of the task and for a norm of conservation at the end of the task.

To offer a motivational account for the effects of physical distance, we assume that the motive to conform becomes stronger when people are acting close to each other. As a measure for the hidden conformity motive, we adopt the assumption of Interdependence Theory that individuals engage in information-seeking behavior that is directly relevant to their motivational goals (see Kelley \& Thibaut, 1978; Rusbult \& Van Lange, 1996, p. 578). Consequentially, we asked participants how important the behavior of the others was for their own decisions and expected that it was more important for people who acted closer to each other. The scores on this item serve as a mediator in a separate mediation analysis.

\section{METHOD}

\section{Participants and experimental design}

A total of 83 persons participated in the study ( 45 female, 28 male, average age 24 years). The 43 participants in the big distance condition (21 female, 22 male, average age 26 years) were recruited via one of several web laboratories such as the Web Experimental Psychology Lab (see Reips, 2001). The 40 participants in the low distance condition ( 24 female, 16 male, average age 22) were University of Zurich undergraduates recruited in a lecture.

The experimental design was a 2 (perceived group norm: ecologically efficient vs inefficient) $\times 2$ (physical distance: large vs small) $\times 2$ (pool size: large vs small) mixed model ANOVA with the first and second variable being between-subjects and the third variable being within-subject. Participants were randomly assigned to one of the perceived group norm conditions. The primary dependent variable was participants' consumption from the common pool. To explain the effects of physical distance with a mediation analysis, we also measured the level of importance that participants attached to the group norm as a secondary dependent variable. 


\section{Procedure}

Participants were welcomed to the website (see Footnote 1) with text and pictures that introduced them to the collective use of solar energy and invited them to participate in a scientific experiment. They were informed that the experiment would take 30 to 40 minutes and that they could possibly win cash prizes. After clicking on an OK button to signal their willingness to participate, they were randomly assigned to one of the two group norm conditions (efficient vs inefficient). Subsequently, participants entered their demographic information and e-mail address. Once participants had agreed to participate in the experiment, they had to log into a group of players. This led them to believe from the start that they were interacting, through computers, with real people. An indicator on-screen (see top of Figure 1) showed that two people had already logged in; it jumped to three when the participant joined. This procedure created the impression that it would not be long before a total of six participants had logged into the group. To maintain the impression that the participant was interacting with other people throughout the entire commons dilemma task,

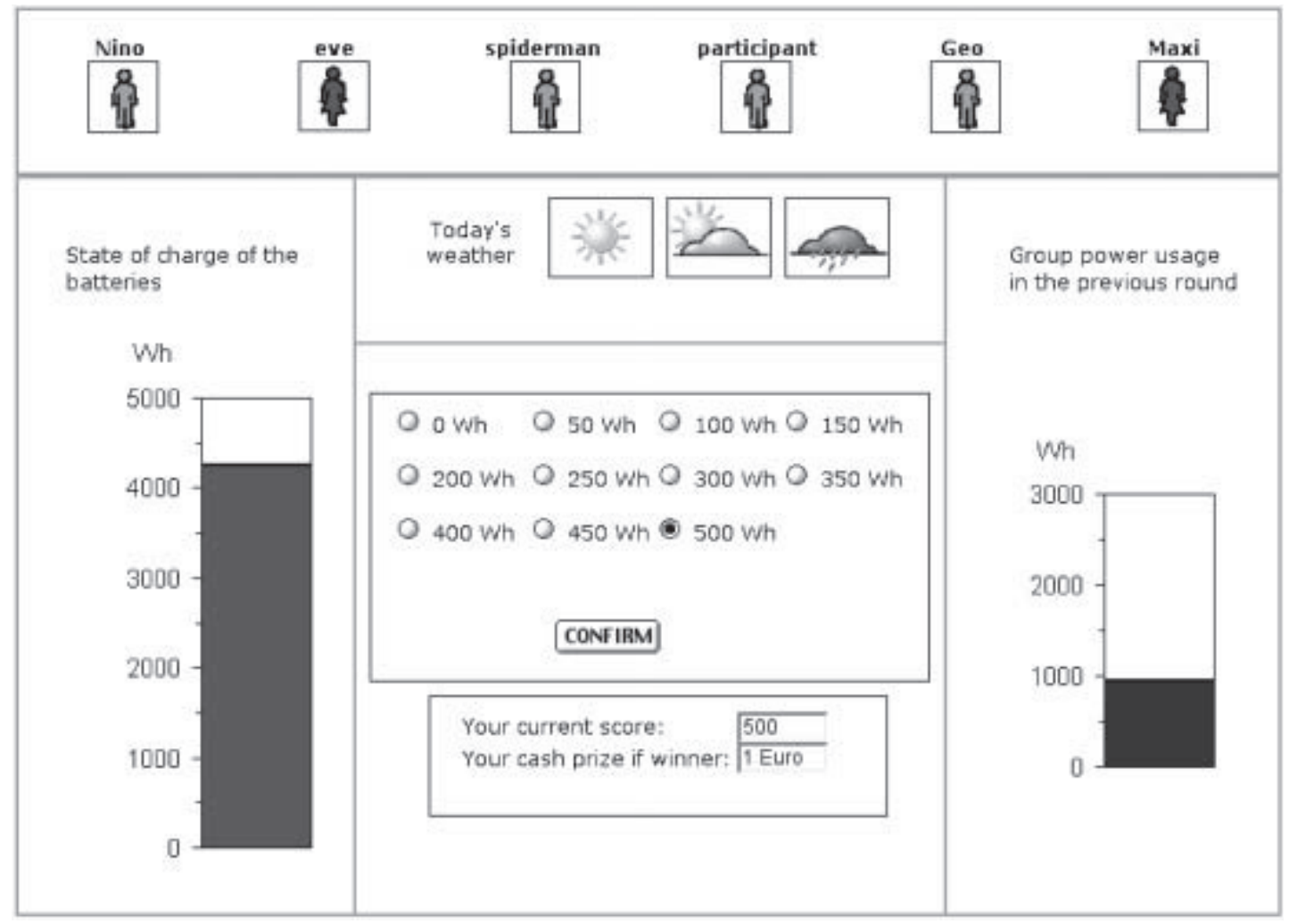

Figure 1. The user interface of the Solar Energy Group Game (SEGG). On the left is the feedback about pool size (i.e., the batteries), on the right the feedback about group usage, near the top the depiction of the group members and the feedback about the regeneration rate (i.e., the weather), and in the center the behavioral options, the related score, and the possible cash prize if winner in a lottery. 
all six people were represented on-screen by figures labeled with their log-in names (see top of Figure 1). Then, after receiving detailed instructions on the screen, participants accomplished the commons dilemma task and filled out more questionnaires containing items for the secondary dependent variable, manipulation checks, and other questions unrelated to the present study. All participants were debriefed by e-mail after completion of the data collection.

\section{Commons dilemma task}

In the SEGG paradigm the common pool is represented by a shared solar power supply. The task's user interface, as it appeared to participants in each round of the task, is shown in Figure 1. Participants had to make 18 consecutive decisions from 11 options of energy use in 50 watt-hours (Wh) increments from $0 \mathrm{Wh}$ to $500 \mathrm{Wh}$. The use of energy was equated with increasing quality of life. Each Wh consumed gave the participant one point for quality of life. Participants were told that they would possibly receive one Euro (approximately US\$ 1.25) for 500 points, depending on the outcome of a lottery. At the same time, the social dilemma structure of the task was emphasized. The more a participant consumed the more he or she could possibly win, but the longer the group was able to maintain the power supply, the longer they could consume energy and the more everyone could possibly win. After completion of the study, five participants were randomly drawn - independent of their outcomes in the task - and each received a prize of 20 Euro (approximately US\$25) via standard mail.

\section{Manipulation of independent variables}

Manipulation of pool size. Although pool size per se is not an independent variable in the present study, it was necessary to manipulate it in order to operationalize the group norm and its ecological efficiency. Therefore, a red indicator at the left-hand side of the user interface (see Figure 1) displayed the pool size from 0 to $5000 \mathrm{Wh}$. The pre-programmed development of the pool size created the impression that the pool had been maintained on a high and stable level in the first six trials of the experiment (pool sizes in stage one: 4250; 4000; 4200; 3950; 4100; 4250), decreased in the second six trials (pool sizes in stage two: 3900; 3500; 3100; 2800; 2500; 2250), and finally fell to nearly zero in the last six rounds (pool sizes in stage three: $1850,1650,1500,1200,900,750){ }^{3}$ This way, stages one and three

\footnotetext{
${ }^{3}$ Another way of manipulating pool size within-subjects would have been to begin with a small pool size and then to make a transition to a large pool. However, we chose the present manipulation as we consider it to come closer to a real-world scenario. Actors are often confronted with decreasing natural resources but seldom with an increasing one. We believe this pool development to be more relevant for conservation behavior.
} 
represented a large pool and a small pool, respectively. Stage two was mainly implemented to make a smooth transition of the pool size from being large to being small. The internal dynamics of the pool were represented by information about the current weather (see Figure 1). The pool (i.e., the amount of solar energy) regenerated more if it was sunny than if it was cloudy or even rainy.

Manipulation of group norm and its ecological efficiency. A blue indicator at the right-hand side of the user interface (see Figure 1) displayed the preprogrammed total consumption of solar energy by the group from $0 \mathrm{Wh}$ to the maximum collective usage of $3000 \mathrm{Wh}(6 \times 500 \mathrm{Wh})$. By definition, the ecological efficiency of a group norm is a function of the pool's size and others' behavior. Therefore, the pre-programmed feedback about the group's consumption changed during the course of the commons dilemma task as a function of the group norm condition. For participants in the "inefficient group norm" condition a low group consumption in stage one (average individual consumption: $185 \mathrm{Wh}$ ) was followed by a high group consumption in stage three (average individual consumption: $358 \mathrm{Wh}$ ). For participants in the "efficient group norm" condition a high group consumption in stage one (average individual consumption: $322 \mathrm{Wh}$ ) was followed by a low group consumption in stage three (average individual consumption: $171 \mathrm{Wh}$ ). In stage two the consumption behavior of the group was similar in both conditions ( $270 \mathrm{Wh}$ vs $260 \mathrm{Wh}$ ), so no particular group norm should be evoked. The behavior in the transition stage was highly similar in all four between-subjects conditions (see Figure 2 on p. 128). Including the transition stage in the data analysis does not alter the relevant results of this study and all reported effects remain significant.

Manipulation of physical distance. The perceived physical distance between the participant and the others was manipulated in a straightforward way by varying the mode of participation in the experiment. Participants either came to the laboratory (small distance condition) or they participated at home - or at any other place - via the Internet (large distance condition). In the "small distance" condition, participants were met by the experimenter at appointed times in the hall of a university building. They were brought to a room with a computer workstation and received the information that they were connected via the Internet to five other participants sitting in separate rooms of the same building. It was emphasized that they were acting anonymously, and that they would not meet the other members of the group after the task. The experimenter left the room for a few minutes, supposedly to go to the other members of the group, while the participant was reading the welcome page, and then returned to give the permission to begin the task. The experimenter then left the room again. When the task was 
completed the participant was thanked and released. The commons dilemma task itself was completely identical to the one for participants in the "large distance" condition. Participants in the "large distance" condition completed the experiment on their own at home or any other place equipped with a computer and a connection to the Internet. Therefore, they perceived the distance between them and the other participants as naturally a lot larger than participants in the "small distance" condition. Inspections of the log files discovered no systematic drop-out in this condition. Once a participant had begun the experiment, it was always completed in about the same time as in the laboratory, on average.

Measurement of dependent variables. As for the primary dependent variable, we analyzed participants' six consecutive consumption decisions in stage one (i.e., large pool) and their six consecutive decisions in stage three (i.e., small pool). In both cases, we pooled these six decisions to an average consumption behavior. As for the secondary dependent variable, we asked participants after the first stage (i.e., large pool) and after the third stage (i.e., small pool): "How important was the information of the group's average usage for your decisions?" (scale: highly important $=1$; not important at all $=5$ ).

Measurements for manipulation checks. We checked the manipulation of group norms by asking participants after stage one and after stage three, "What do you think about the behavior of the other players?" (scale: they use little energy $=1$; they use much energy $=5$ ). Furthermore, we checked the manipulation of pool size by asking participants after stages one and three "What happened to the state of charge of the batteries during rounds 1 through 6 ? [13 through 18, respectively]" (scale: it dropped = 1; it went up $=5$ ).

\section{RESULTS}

\section{Manipulation checks}

A repeated measures ANOVA on the item measuring the perceived group norm revealed a significant within-subject interaction effect between stages and group norm $F(1,79)=29.71, p<.001, \eta^{2}=.27$. In both stages, the simple main effects of the group norm were significant, $F \mathrm{~s}(1,81)=12.9$ vs $11.0, p<.001$. In stage one, participants in the "efficient group norm" condition $(M=2.92, S D=0.89)$ perceived others' consumption to be higher than participants in the "inefficient group norm" condition $(M=$ $2.30, S D=0.66)$. In stage three, it was vice versa $(M=3.81, S D=0.88$ vs $M=4.54, S D=0.62)$. Thus, the pre-programmed feedback about others' 
consumption was perceived as intended by our manipulation. Physical distance and pool size had no effect on the perception of group norms, $F \mathrm{~s}<1$.

A repeated measures ANOVA on the item measuring the perceived size of the pool revealed a within-subject effect for pool size, $F(1,79)=884.8, p<$ $.001, \eta^{2}=.92$. Participants perceived a steady large pool in stage one $(M=$ $3.04, S D=0.40)$ and a sharply declined pool in stage three $(M=1.14, S D=$ 0.35 ). This shows that the participants perceived the difference between the large pool condition and the small pool condition as intended by the manipulation. Physical distance and the group norm had no significant effects on the perception of the pool, $F \mathrm{~s}<1$.

\section{Consumption behavior}

We analyzed participants' consumption decisions in absolute numbers with a 2 (group norm: ecologically efficient vs inefficient) $\times 2$ (physical distance: large vs small) $\times 2$ (pool size: large vs small) analysis of variance (ANOVA) with repeated measures on the last factor. The means resulting from this analysis are shown in Table 1 where all subsequently reported effects are labeled with subscripts.

As expected, the analysis revealed no between-subjects effects. Of particular importance, people participating at home and people participating in the laboratory did not differ in their overall consumption, and there was no interaction between physical distance and pool size either. This shows that the two modes of participating in the experiment did not evoke different reactions to the decreasing pool. However, a within-subject effect of pool size was found, $F(1,79)=181.7, p<.001, \eta^{2}=.70$, indicating that participants consumed more when the pool was large than when it was small (see Table 1, comparison a). The average consumption dropped from 370.7 $(S D=98.9)$ to $196.5(S D=124.8)$, showing that the participants generally adapted their consumption behavior to the deteriorating pool.

More important, the within-subject effect of pool size was qualified by an interaction with the group norm, $F(1,79)=47.6, p<.001, \eta^{2}=.38$, and the simple main effects of group norm were significant in both stages, with a large pool, $F(1,79)=7.9, p<.01, \eta^{2}=.09$ (for means, see Table 1, comparison b), and with a small pool, $F(1,79)=25.1, p<.01, \eta^{2}=.24$ (for means, see Table 1, comparison c). Taking a closer look at the means in Table 1, with a large pool participants getting feedback about the group's low use consumed less than those getting feedback about the group's high use $(M \mathrm{~s}=343.1$ vs 405.0). Furthermore, they not only followed the feedback about a high and efficient group norm of $322 \mathrm{Wh}$ but went significantly beyond it by taking $405.0 \mathrm{Wh}, t(36)=5.46, p<.01$. Participants also followed the feedback about a low and inefficient group 
norm of $185 \mathrm{Wh}$ to some degree, but their average consumption of $343.1 \mathrm{Wh}$ did not even come close to it. With a small pool, on the other hand, participants receiving feedback about the group's low consumption consumed less than those receiving feedback about the group's high consumption ( $M \mathrm{~s}=126.6$ vs 252.7$)$. Again, participants not only followed the feedback about a low and efficient group norm of $171 \mathrm{Wh}$ but significantly went below it by consuming $126.6 \mathrm{Wh}$ on average, $t(36)=$ $-2.77, p<.01$. And once again, participants also followed the feedback about an inefficient group norm of $358 \mathrm{Wh}$ to some degree, but did not even come close to it by consuming $252.7 \mathrm{Wh}$ on average. As expected, this pattern of results shows that participants generally tended to adapt their consumption to the feedback about the group's consumption, whether it was high or low. Additionally, and in line with our hypothesis, conformity effects were stronger when the group norm was ecologically efficient.

Most interestingly, the analysis also revealed the predicted three-way interaction between pool size, group norm, and physical distance, $F(1,79)=$ $6.5, p<.05, \eta^{2}=.08$. When the pool size was large, the interaction between physical distance and group norm became significant, $F(1,79)=3.9, p<$ $.05, \eta^{2}=.05$. In that first stage, simple effects analyses of group norm within the single conditions of physical distance showed that only in the small distance condition did a significant difference appear between people receiving feedback about the group's high consumption and people getting

TABLE 1

individuals' consumption behavior

\begin{tabular}{|c|c|c|c|c|c|c|c|}
\hline \multirow[b]{3}{*}{ Pool size } & \multirow{3}{*}{$\begin{array}{l}\text { Perceived } \\
\text { group norm }\end{array}$} & \multicolumn{4}{|c|}{ Physical distance } & \multirow[b]{3}{*}{ Total M } & \multirow[b]{3}{*}{ Grand $M$} \\
\hline & & \multicolumn{2}{|c|}{$\begin{array}{c}\text { Large } \\
\text { (Internet) }\end{array}$} & \multicolumn{2}{|c|}{$\begin{array}{c}\text { Small } \\
\text { (laboratory) }\end{array}$} & & \\
\hline & & $M$ & $S D$ & $M$ & $S D$ & & \\
\hline \multirow[t]{2}{*}{ Large } & $\begin{array}{l}\text { Inefficient, } \\
\qquad n=46 \text { (low use) }\end{array}$ & 353.0 & 89.8 & $327.8_{\mathrm{d}}$ & 106.2 & $343.1_{\mathrm{b}}$ & $370.7_{\mathrm{a}}$ \\
\hline & $\begin{array}{l}\text { Efficient, } \\
\quad n=37 \text { (high use) }\end{array}$ & $370.6_{\mathrm{g}}$ & 109.7 & $428.4_{\mathrm{d}, \mathrm{g}}$ & 72.0 & $405.0_{\mathrm{b}}$ & \\
\hline \multirow[t]{2}{*}{ Small } & $\begin{array}{l}\text { Inefficient, } \\
\qquad n=46 \text { (high use) }\end{array}$ & $249.7_{\mathrm{f}}$ & 107.3 & $257.4_{\mathrm{e}}$ & 132.0 & $252.7_{\mathrm{c}}$ & $196.5_{\mathrm{a}}$ \\
\hline & Efficient, $n=37$ (low use) & $152.8_{\mathrm{f}}$ & 127.7 & $108.7_{\mathrm{e}}$ & 68.1 & $126.6_{c}$ & \\
\hline Grand $M$ & & 287.5 & & 279.4 & & & 283.5 \\
\hline
\end{tabular}

Means and standard deviations of individuals' consumption behavior by group norm, physical distance, and pool size. Higher values represent higher consumption on a scale from 0 to 500 (Wh). Values with the same subscript differ at $p<.05$ and are referred to in the results section as comparisons between particular cells. $N=83$. 
feedback about the group's low consumption, $F(1,79)=11.5, p<.001, \eta^{2}$ $=.13$ (for means, see Table 1, comparison d). In support of our hypothesis, the group norm manipulation in the first stage affected participants who were close to each other in the laboratory (327.8 vs 428.4 ) but not those who were farther apart (353.0 vs 370.6). Furthermore, only the increase in consumption due to the feedback about the group's high and efficient use turned out to be a significant effect of physical distance, $F(1,35)=3.8, p=$ $.05, \eta^{2}=.10$ (for means, see Table 1, comparison $\mathrm{g}$ ), but the decrease due to the feedback about the group's low and inefficient use was not. In support of our hypothesis, the physical distance between participants had a significant effect on behavior only when the perceived group norm was ecologically efficient. When the group norm was inefficient, the effect of physical distance disappeared.

In contrast, when the pool size was small we did not find an interaction between physical distance and group norms, $F=1.1$. Participants in the Internet and in the laboratory showed significant reactions to the group norm (for means, see Table 1, comparisons e and f), although there is a clear trend that laboratory participants reacted more strongly than Internet participants, especially when the feedback about the group's use was low, $F$ $=1.9$. When the feedback about the group's use was high and the pool size was small the physical distance no longer made a difference, $F<1$. To summarize, with a small pool size there was a tendency towards larger effects of physical distance on behavior when the perceived group norm was ecologically efficient.

For further illustration, Figure 2 shows the reported three-way interaction between group norms, physical distance, and pool size. Participants following an efficient group norm differed between the conditions of physical distance when the pool size was large, and showed at least such a tendency when it was small (black bars vs white bars). However, participants following an inefficient group norm did not (light gray bars vs dark gray bars). Figure 2 also shows the transition stage where behavior in all conditions was very similar.

\section{The importance of others' behavior as mediator}

The answers on the corresponding item were analyzed with a 2 (group norm: ecologically efficient vs inefficient) $\times 2$ (physical distance: large vs small) $\times$ 2 (pool size: large vs small) analysis of variance (ANOVA) with repeated measures on the last factor. As expected, the analysis revealed a betweensubjects effect of physical distance, $F(1,79)=4.8, p<.05, \eta^{2}=.06$. Participants in the laboratory $(M=4.39 ; S D=1.19)$ attached more importance to the group norm than participants in the Internet $(M=4.01$; 


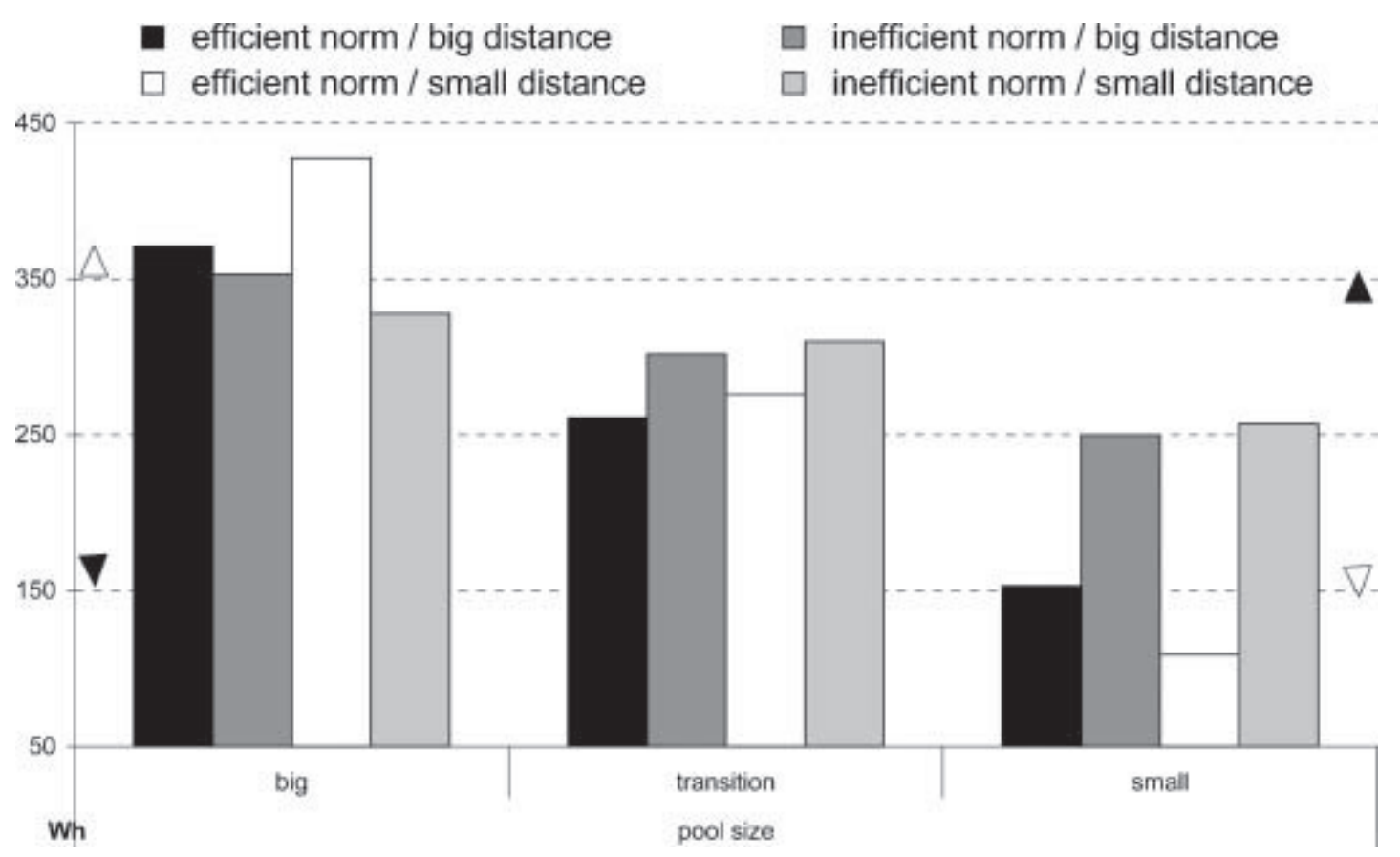

Figure 2. Average consumption behavior per round (in Wh) as a function of group norm (efficient vs inefficient), physical distance (laboratory vs Internet), and pool size (large vs small). White triangles at the left and right border of the diagram indicate the feedback about an ecologically efficient group norm ( $322 \mathrm{Wh}$ with a large pool, $171 \mathrm{Wh}$ with a small pool). Black triangles, in contrast, indicate the feedback about an ecologically inefficient group norm (185 Wh with a large pool, $358 \mathrm{Wh}$ with a small pool).

$S D=1.10)$. This result supports our assumption of a diminished importance of group norms to participants who are physically farther apart.

Because significant behavioral effects are a precondition for a mediation analysis, we could only conduct it in conditions where physical distance had shown significant main effects on consumption behavior. Although in our previous analyses of consumption behavior significant interactions have shown that physical distance indeed moderates the effect of group norms in a theoretically reasonable manner, only one simple main effect reached significance. This was the case when pool size was large and the group norm was efficient (see Table 1, comparison g, $n=37$ ). Consequently, we applied the mediation analyses procedure to this particular condition only.

Applying the procedure of Baron and Kenny (1986), we conducted three regression analyses to test for mediation. In the first analysis, we found an overall effect of physical distance on mean consumption when the pool was large and the group norm was efficient, $\beta=.31, t(36)=1.94, p=.05$. Participants in the small-distance condition $(M=428.4 ; S D=72.0)$ adapted more strongly to the feedback about the group's high use and took more resources than participants in the large-distance condition $(M=370.6$; $S D=109.7)$. In the second analysis, physical distance was predictive of the 
amount of reported importance, $\beta=.41, t(36)=2.69, p<.01$. Participants in the small-distance condition $(M=4.39 ; S D=1.19)$ found others' behavior to be more important than participants in the large-distance condition $(M=4.01 ; S D=1.10)$. In the third analysis, including both physical distance and the importance score into the equation simultaneously, the unique effect of importance of others' behavior became significant, $\beta=.41, t(36)=2.49, p<.05$, and the unique effect of physical distance on consumption behavior became unreliable, $\beta=.14, t(36)$ $=0.87$.

Using the Sobel test (see Kenny, Kashy, \& Bolger, 1998), we found that the reduction in effect size attributable to the importance score was marginally significant, $Z=1.83, p=.07$. Thus, we obtained preliminary evidence that the effect of physical distance on consumption behavior was mediated by the level of importance participants attached to the group norm, as was expected according to our motivational approach.

\section{DISCUSSION}

The present results extend previous research on group norms in commons dilemmas by showing that conformity is strongest when the physical distance between the actors is small and the perceived group norm is ecologically efficient. Furthermore, our results confirm the general importance of group norms in common pool resource management by replicating earlier research with a different experimental design. With the present design, we were able to show that people tend to follow the feedback about a group's high consumption and low consumption when resources are abundant and when they are scarce, but always constrain their behavior by considerations of ecological efficiency. In the following sections, we discuss our findings in the light of previous commons dilemma research and social psychological theories, present limitations of the present study as well as possible future directions, and conclude by highlighting the societal implications of our findings.

While psychological variables such as causal attributions (e.g., Rutte et al., 1987) or individual characteristics (e.g., Kramer et al., 1986; Messick et al., 1983) have been studied and found to moderate conformity effects, the environmental variable of physical distance between the people who share a common pool has been forgotten. Physical distance clearly and widely varies in common pools; distance between the actors is greater in global than in local resource management. While some resources, such as forests, are often managed by a local group, others such as the earth's atmosphere often include a global group of users. Based on Latané's Theory of Social Impact (1981) the results of the present study show that physical distance does indeed influence people's bias towards group norms. Individuals who were 
sharing a common pool close to each other in the laboratory were more inclined to follow the feedback of an efficient group norm than people who were farther apart on the Internet.

On the one hand, the present results extend the validity of Latané's Theory of Social Impact to the domain of consumption behavior in common pool resource management. To date, it has mostly been applied to cognitive domains such as the frequency of memorable interactions with others (see Latané et al., 1995), and in rare cases also to overt behavior such as buying decisions in a retail store (Argo et al., 2005). In a general sense, therefore, our data support the view that physical space is an important and often neglected concept for the study of social influence in daily life. On the other hand, we have also brought forward a motivational explanation for the distance effect on behavior: By taking the importance of the group's behavior as an indicator for the underlying motive to conform (see Kelley \& Thibaut, 1978), a mediation analysis has confirmed that the motive to conform to the group's behavior weakened with increasing physical distance from those others, which led to reduced conformity. Thus, the effect of physical distance, as predicted by Latané's Theory of Social Impact, on consumption behavior in a commons dilemma may have motivational roots. When the distance between actors becomes larger they may be less motivated to follow others' behavior.

According to Wilke's (1991) GEF hypothesis, besides greed and fairness, one other motive is guiding behavior in common pool resource management - the motive to manage the pool efficiently. Previous research has shown the fairness and the efficiency motives to conflict sometimes in commons dilemmas (e.g., Messick, 1986; Samuelson et al., 1986). People are more inclined to follow others' overuse when the resource is abundant, and others' conservation behavior when it is scarce. They are less inclined to follow others' overuse in times of scarcity and others' conservation behavior in times of abundance, because they would then face a conflict between conformity and efficiency.

The present results corroborate these ideas by showing that people not only followed efficient group norms but also went significantly beyond them, especially when being close to each other. In contrast, people were also guided by inefficient group norms to some degree but stayed far from adjusting their own behavior to the group norm. Stressing the importance of ecological efficiency, closer physical distance only led to increased conformity when the respective group norm was ecologically efficient. In contrast, when the group norm was ecologically inefficient, physical distance didn't make a difference. In this latter case, people's behavior may primarily be guided by the motive to use the pool efficiently, and conformity issues, such as the physical distance between actors, may move into the background. In sum, the present results show that people are indeed 
following different motivations when using a common pool, and these motives can either conflict or harmonize, as is postulated by the GEF hypothesis.

\section{Limitations and future directions}

The question to what degree social processes have local vs global character, and what role physical distance may take in social processes, is an important one in modern theories and simulation models in the social sciences. With respect to social dilemmas there are several computer simulation studies examining the effects of space on behavior (e.g., Hauert, de Monte, Hofbauer, \& Sigmund, 2002; Nowak, Latané, \& Lewenstein, 1994; Nowak \& May, 1992; Nowak, Szamrey, \& Latané, 1990). Empirical research, especially experimental studies, lags behind simulation models in this area. The present paper may serve to help fill this gap. However, several critical issues of the present study have to be mentioned.

The manipulation of physical distance by using an Internet sample and comparing it to a laboratory sample in the present study may be seen as an issue. The Internet sample was not controlled and people may have participated in many different ways, for example in a public library or at home while eating or watching TV. Therefore, participants in the laboratory may have been more focused on the task than the participants in the uncontrolled sample. The fact that the two groups did not differ in terms of their reactions to the declining pool can be taken as evidence, however, that they completed the task with equal concentration and equal seriousness. As intended by the manipulation, the two groups only differed in their reactions to the feedback about the group's consumption behavior serving as a descriptive norm.

Apart from the smaller physical distance between participants in the laboratory, we cannot think of a systematic difference between the laboratory sample and the Internet sample that may have evoked the articulate effects of conformity in the present data. Possible confounds such as group identity, enhanced entitativity, or other group processes must have played a similar role for people at home and people coming to the laboratory, because in both groups the group was represented in exactly the same way on the screen during the commons dilemma task. Furthermore, both groups acted with the same degree of anonymity, as they were all alone during the task, and none of them did expect to meet the other members of the group after completion of the task. Finally, we have employed several techniques to ensure the quality of the data collected via the Internet, such as drop-out analyses and IP checks, to control for repeated participation (see Reips, 2002a, 2002b; Ryf, 2003). Nevertheless, in future studies with a similar design, people's perceptions of physical distance should be measured 
explicitly and possible confounds such as the ones mentioned above should be controlled for.

Future commons dilemma studies may also put an even stronger emphasis on the motivational bases of consumption behavior and related issues such as conformity to group norms. They may include the third important motive of greed by assessing people's social values, for example, and relate them to physical distance and conformity behavior (e.g., Kramer et al., 1986). Furthermore, survey research and field studies could tackle the question whether physical distance does indeed make a difference for different kinds of common pool resources (e.g., Schultz, 2002). Finally, there could be other relevant moderators of conformity behavior in common pool resource management, for example the level of anonymity (e.g., Kerr, 1999). Anonymous individuals may be less inclined to follow others' consumption behavior than identifiable individuals because they can't be made responsible or sanctioned (e.g., De Cremer \& Bakker, 2004).

\section{Concluding remarks}

The present study shows how insights from experimental social psychology can contribute to solutions for the successful management of common pool resources. At the same time, it is an example of how research on environmental behavior can substantiate and advance social psychology (see Stern, 2000). As this study has shown, the consumption behavior of others had a stronger impact on an individual's own consumption when these others were close and the perceived social norm was ecologically efficient. In a small neighborhood, for example, conservation behavior could be spread through the communication of conservational group norms, especially when it is ecologically efficient (e.g., during a crisis). For example, if a neighbor is seen to save water during a hot summer, others in the neighborhood are probably inclined to do the same. With global common pool resources, in contrast, group norms are less effective instruments for behavioral change, even if the ecological situation would demand such a change. Fortunately, in many instances of global resources (e.g., the greenhouse effect caused by private mobility) local behavior implying small interpersonal distances plays a major role.

\section{REFERENCES}

Argo, J. J., Dahl, D. W., \& Manchanda, R. V. (2005). The influence of a mere social presence in a retail context. Journal of Consumer Research, 32, 207-212. 
Baron, R. M., \& Kenny, D. A. (1986). The moderator-mediator distinction in socialpsychological research: Conceptual, strategic, and statistical considerations. Journal of Personality and Social Psychology, 51, 1173-1182.

Brucks, W. M. (2004). Kollektive Ressourcenbewirtschaftung aus sozialpsychologischer Perspektive. [A social psychological perspective on collective resource management]. Lengerich, Germany: Pabst.

Cialdini, R. B., Kallgren, C. A., \& Reno, R. R. (1991). A focus theory of normative conduct: Recycling the concept of norms to reduce littering in public places. Journal of Personality and Social Psychology, 58 (6), 1015-1026.

Crutchfield, R. A. (1955). Conformity and character. American Psychologist, 10, 191-198.

De Cremer, D., \& Bakker, M. (2004). Accountability and cooperation in social dilemmas: The influence of others' reputational concerns. Current Psychology, 22 (2), 155-163.

Hart, J. W., Stasson, M. F., \& Karau, S. J. (1999). Effects of source expertise and physical distance on minority influence. Group Dynamics: Theory, Research, and Practice, 3 (1), 81-92.

Hauert, C., De Monte, S., Hofbauer, J., \& Sigmund, K. (2002). Volunteering as a red queen mechanism for cooperation in public goods games. Science, 296, 1129-1132.

Jackson, J. M. (1986). In defense of social impact theory: Comment on Mullen. Journal of Personality and Social Psychology, 50 (3), 511-513.

Jackson, J. M., \& Latané, B. (1981). All alone in front of all those people: Stage fright as a function of number and type of coperformers and audience. Journal of Personality and Social Psychology, 40, 73-85.

Kallgren, C. A., Reno, R. R., \& Cialdini, R. B. (2000). A focus theory of normative conduct: When norms do and do not affect behavior. Personality and Social Psychology Bulletin, 26 (8), 1002-1012.

Kelley, H. H., \& Thibaut, J. W. (1978). Interpersonal relations: A theory of interdependence. New York: John Wiley \& Sons.

Kenny, D. A., Kashy, D. A., \& Bolger, N. (1998). Data analysis in social psychology. In D. T. Gilbert, S. T. Fiske \& G. Lindzey (Eds.), The handbook of social psychology (4th ed., pp. 233-265). New York: McGraw-Hill.

Kerr, N. L. (1995). Norms in social dilemmas. In D. A. Schroeder (Ed.), Social dilemmas: Perspectives on individuals and groups (pp.31-47). Westport, CT: Praeger.

Kerr, N. L. (1999). Anonymity and social control in social dilemmas. In M. Foddy, M. Smithson, S. Schneider \& M. Hogg (Eds.), Resolving social dilemmas (pp. 103-118). Philadelphia: Psychology Press.

Knowles, E. S. (1983). Social physics and the effects of others: Tests of the effects of audience size and distance on social judgments and behaviors. Journal of Personality and Social Psychology, 45, 1263-1279.

Knowles, E. S. (1999). Distance matters more than you think! An artifact clouds interpretation of Latané, Liu, Nowak, Bonevento, and Zheng's results. Personality and Social Psychology Bulletin, 25 (8), 1045-1048.

Kopelman, S., Weber, M. J., \& Messick, D. M. (2002). Factors influencing cooperation in commons dilemmas: A review of experimental psychological research. In E. Ostrom, T. Dietz, N. Dolsak, P. C. Stern, S. Stovich \& E. U. Weber (Eds.), The drama of the commons (pp. 113-156). Washington: National Academy Press.

Kramer, R. M., McClintock, C. G., \& Messick, D. M. (1986). Social values and cooperative response to a simulated resource conservation crisis. Journal of Personality, 54, 576-592.

Latané, B. (1981). The psychology of social impact. American Psychologist, 36 (4), 343-356.

Latané, B. (1996). Dynamic social impact. In R. Hegselmann, U. Mueller \& K. G. Troitzsch (Eds.), Philosophy and methodology of the social sciences (Vol. 23, pp. 287-310). Dordrecht: Kluwer Academic Publishers. 
Latané, B., \& Harkins, S. (1976). Cross-modality matches suggest anticipated stage fright a multiplicative power function of audience size and status. Perception and Psychophysics, 20, 482-488.

Latané, B., Liu, J. H., Nowak, A., \& Bonevento, M. (1995). Distance matters: Physical space and social impact. Personality \& Social Psychology Bulletin, 21 (8), 795-805.

Lott, D. F., \& Sommer, R. (1967). Seating arrangement and status. Journal of Personality and Social Psychology, 7, 90-95.

Messick, D. M. (1986). Decision making in social dilemmas: Some attributional effects. In B. Brehmer, H. Jungermann, P. Lourens \& G. Sevon (Eds.), New directions in research on decision making (pp. 219-227). North-Holland: Elsevier Science Publishers B.V.

Messick, D. M., Wilke, H., Brewer, M. B., Kramer, R. M., Zemke, P. E., \& Lui, L. (1983). Individual adaptations and structural change as solutions to social dilemmas. Journal of Personality and Social Psychology, 44 (2), 294-309.

Monge, P. R., Rothman, L. W., Eisenberg, E. M., Miller, K. I., \& Kirste, K. K. (1985). The dynamics of organizational proximity. Management Science, 31 (9), 1129-1141.

Mullen, B. (1985). Strength and immediacy of sources: A meta-analytic evaluation of the forgotten elements of social impact theory. Journal of Personality and Social Psychology, 48 (6), 1458-1466.

Mullen, B. (1986). Effects of strength and immediacy in group context: Reply to Jackson. Journal of Personality and Social Psychology, 50 (3), 514-516.

Nowak, A., Latané, B., \& Lewenstein, M. (1994). Social dilemmas exist in space. In U. Schulz, W. Albers \& U. Mueller (Eds.), Social dilemmas. Heidelberg: Springer.

Nowak, A., \& May, R. (1992). Evolutionary games and spatial chaos. Nature, 359, 826-829.

Nowak, A., Szamrej, J., \& Latané, B. (1990). From private attitude to public opinion: A dynamic theory of social impact. Psychological Review, 97 (3), 362-376.

Reips, U-D. (2001). The Web Experimental Psychology Lab: Five years of data collection on the Internet. Behavior Research Methods, Instruments, \& Computers, 33, 201-211.

Reips, U-D. (2002a). Internet-based psychological experimenting - Five do's and five don'ts. Social Science Computer Review, 20 (3), 241-249.

Reips, U-D. (2002b). Standards for internet-based experimenting. Experimental Psychology, 49 (4), 243-256.

Reips, U-D., \& Stieger, S. (2004). Scientific LogAnalyzer: A web-based tool for analyses of server $\log$ files in psychological research. Behavior Research Methods, Instruments, \& Computers, 36 (2), 304-311.

Rusbult, C. E., \& Van Lange, P. A. M. (1996). Interdependence processes. In T. Higgins \& A. Kruglanski (Eds.), Social psychology: Handbook of basic principles (pp. 564-596). New York: Guilford.

Rutte, C. G., Wilke, H. A. M., \& Messick, D. M. (1987). Scarcity or abundance caused by people or the environment as determinants of behavior in the resource dilemma. Journal of Experimental Social Psychology, 23, 208-216.

Ryf, B. (2003). Kooperation in Ressourcenkrisen: Ein on-loffline Vergleich [Cooperation in resource crises: An on-loffline comparison]. Unpublished Diploma Thesis, University of Zurich, Switzerland.

Samuelson, C. D., Messick, D. M., Wilke, H. A. M., \& Rutte, C. G. (1986). Individual restraint and structural change as solutions to social dilemmas. In H. A. M. Wilke, D. M. Messick \& C. G. Rutte (Eds.), Experimental social dilemmas (pp.29-53). Frankfurt am Main: Verlag Peter Lang.

Schroeder, D. A., Jensen, T. D., Reed, A. J., Sullivan, D. K., \& Schwab, M. (1983). The actions of others as determinants of behavior in social trap situations. Journal of Experimental Social Psychology, 19, 522-539. 
Schultz, P. W. (2002). Knowledge, information, and household recycling: Examining the knowledge deficit model of behavior change. In T. Dietz \& P. C. Stern (Eds.), New tools for environmental protection: Education, information, and voluntary measures (pp.67-82). Washington, DC: National Academy Press.

Sedikides, C., \& Jackson, J. M. (1990). Social impact theory: A field test of source strength, source immediacy and number of targets. Basic and Applied Social Psychology, 11 (3), 273-281.

Stern, P. C. (2000). Psychology and the science of human-environment interaction. American Psychologist, 55 (5), 523-530.

Talarowski, F. S. (1982). Attitudes toward and perception of water conservation in a Southern California community. Dissertation, University of California, Santa Barbara.

Valacich, J. S., George, J. F., Nunamaker, J. F., \& Vogel, D. R. (1994). Physical proximity effects on computer-mediated group idea generation. Small Group Research, 25 (1), 83-104.

Wilke, H. A. M. (1991). Greed, efficiency and fairness in resource management situations. In W. Stroebe \& M. Hewstone (Eds.), European review of social psychology (Vol.2, pp. 165187). Chichester, UK: Wiley.

Wolf, S., \& Latané, B. (1981). If laboratory research doesn't square with you, then cube it: The potential of interactive TV for social psychological research. Personality and Social Psychological Bulletin, 7, 344-352. 